\title{
Optimal Production Decisions with Emissions trading
}

\author{
ALSHARIF HUSSAIN ZAID H ${ }^{1, a^{*}}$, Jian Zhang ${ }^{2, b}$
}

${ }^{1}$ 130, Meilong Road, East China University of Science and Technology., Shanghai, China 200237

${ }^{2} 130$, Meilong Road, East China University of Science and Technology., Shanghai, China 200237

Aalsharifhz@hotmail.com, bzhjian@ecust.edu.cn

* corresponding author

\begin{abstract}
Keywords: Emission trading; Investment in carbon emission reduction; Optimal Decision
Abstract. To discuss the decision making problem of optimal production in supply chain enterprises, by taking a two-stage supply chain with one supplier and one retailer as the research objective and considering emissions trading, the profit models of both centralized and decentralized supply chains were proposed with logical proof. The conclusions show that given finance demand for products, carbon-trading policy enables members of the supply chain to make more money from investing carbon emissions. In addition, in concentration decision, emission reduction effort best that in decentralized supply chain and all members' profit will grow up if the retailer provide the supplier with appropriate subsidies. Furthermore, customs' low-carbon awareness provides a boost for emission reduction efforts and leads to more benefits to the enterprises
\end{abstract}

\section{Introduction}

Climate change has become a widespread concern global issues, mitigation of climate change is to reduce the emissions of carbon dioxide and other greenhouse gases.

For carbon emissions, many countries or regions of the world have made their own carbon reduction targets. There is no doubt that, faced with the Government's policy of carbon trading and carbon emission reduction requirements of the public, as the subject of carbon emissions, more and more enterprises began to take carbon emissions into decision-making considerations. Blyth(2009) studied the incentive effect of carbon emission price on corporate emission reduction investment. Kockar(2011) discusses the effect of the total emissions cap-and-trade on the corporate production. Zhang(2011) studied production and inventory optimization decision problems of supplier companies faced random demand in the carbon cap-and-trade context. Hua(2011) studied the optimal order quantity problem in the context of carbon trading mechanisms and demanding. But many of these studies focus on individual companies, without the study of whole supply-chain carbon emissions. Of course, there are a few scholars studied carbon emissions from the perspective of supply chain.Benjaafar(2013) took the lead in formulating a simple supply chain system model considering carbon emission factors and draw many meaningful managerial significance, groundbreaking on operational issues in carbon emissions. Hoen(2010) first incorporate carbon costs and carbon emissions policy into the problem of selecting the mode of transportation in the supply chain, and studied the effect of carbon emissions costs and limit two kinds of carbon regulation on transport mode choice of supply chain. Du(2011) considered a new supply chain under the background of carbon emission trading, and by newsboy model he analyzed the game process on both sides of the emission-dependent supply chain. But their study did not specifically consider the problems of cooperation and coordination between members of the supply chain under the policy of carbon trading, and more importantly, does not take into account consumer preferences for low carbon case, carbon trading policies on the supply chain and the supply chain members to optimize the impact of decisions, and how the supply chain reduce carbon emissions by investing in carbon-reduction technology and increase their earnings.

In this paper, a carbon trading policy background, taking into account consumers' appetite for low-carbon, the establishment of decentralized decision making retailers as game models of supply chain leaders and centralized decision-making model, studied how carbon trading and consumer appetite for low-carbon influence on related decisions (coefficient of reduction rate and price 
subsidies) of supply chain upstream and downstream companies, as well as supply chain how to compete and collaborate to achieve their best.

\section{Problem characteristics, notation and assumptions}

Considered by a two-stage supply chain consisting of a supplier and a retailer, retailers occupy the leading position in the supply chain, in order to encourage suppliers to invest more in abatement technologies, retailers give emission reduction products price subsidies $\beta \theta$. This article gave consideration to low-carbon environment, environmental awareness among consumers is also rising, willing to pay higher prices for corporate social responsibility levels (emissions inputs).Supplier invested emissions reduction, as well as translate emissions trading into carbon emission savings for get a portion of their profits, and price subsidies by the retailer.

We assume that, Emissions can be reduced by putting emission reduction technology, the cost of emission reductiongoes up as the emission reduction rate $\theta$ increases and Consumer demand for product before and after reduction $\mathrm{D}$ is unchanged, but consumers have some appetite for low-carbon ones and .Product wholesale prices w before and after emissions reduction is unchanged. In addition, production costs $\mathrm{c}$ in unit before and after the reduction are the same, namely the investment of abatement costs has no effect on production costs in unit.

Some other parameters involved are given as follows:

$\mathrm{pC}$ : price of carbon trading in the carbon trading market;

$\mathrm{e} 0$ :amount of carbon emissions per unit of product;

$\square$ e:After investment in emission reduction technologies to reduce carbon emissions per unit of product

$\pi \mathrm{R}$ : retailer's profit

$\pi \mathrm{s}$ : vendor's profit

$\pi \mathrm{R}+\mathrm{S}$ : the total profit in supply chain system

\section{Analytical model}

\section{The decision-makings of supplier and retailer in Stackbelberg game}

Using the reverse method to solve,supplier determine the emission rate of investment, to maximize her profit, $\max \pi_{s}=\left(w+\beta \theta_{0}\right) D+p_{C} \square e D-I\left(\theta_{0}\right)$. The optimal emission reduction rate of suppliers investment is:

$$
\theta_{0}^{*}=\frac{\left(\beta^{*}+p_{C} e_{0}\right) D}{2 r}
$$

Then, to maximize the retailer's profit, $\max \pi_{R}=\left(a-b D+c \theta_{0}^{*}-w-\beta \theta_{0}^{*}\right) D$. Subsidies coefficient for optimal price that retailers offered to suppliers is:

$$
\beta_{0}^{*}=\frac{c-p_{c} e_{0}}{2}
$$

Then, the optimal emissiom reduction rate is:

$$
\theta_{0}^{*}=\frac{\left(c+p_{C} e_{0}\right) D}{2 r}
$$

Proposition 1: in the retailer as leader supplier in the Stackelberg game models for followers, balanced solution can be obtained as follows:

Supplier's the optimal emission reduction rate of investment: $\theta_{0}^{*}=\frac{\left(c+p_{c} e_{0}\right) D}{2 r}$;

Retailers from increasing their optimum price coefficients: $\beta_{0}^{*}=\frac{c-p_{c} e_{0}}{2}$;

Supplier's optimal profit is: $\pi_{S_{0}}^{*}=w D+\frac{\left(c^{2}+3 p_{c}^{2} e_{0}^{2}\right) D^{2}}{8 r}$; 
Retailer's optimal profit is: $\pi_{R_{0}}^{*}=(a-w) D-b D^{2}+\frac{\left(c+p_{c} e_{0}\right)^{2} D^{2}}{4 r}$;

Total supply chain profit is:

$\pi_{S_{0}+R_{0}}^{*}=\pi_{S_{0}}^{*}+\pi_{R_{0}}^{*}=a D-b D^{2}+\frac{\left(3 c^{2}+4 c p_{c} e_{0}+4 p_{c}^{2} e_{0}^{2}\right) D^{2}}{8 r}$.

From Proposition 1, we can get the conclusions below.

Conclusion 1: low carbon emission rates and consumer preferences and the carbon emissions per unit of product are related.

Conclusion 2: coefficients of price subsidies and consumer appetite for low carbon positive correlation negative correlation with carbon emissions per unit of product.

Conclusion 3: the consumer appetite for low carbon and retailer profits, and supplier profit showed a positive relationship.

\section{The decision-makings of supplier and retailer with coordination}

To maximize the supply chain's profit, $\max \pi_{S+R}=P_{0} D+p_{C} \square e D-I\left(\theta_{0}\right)$.

The optimal emission reduction rate of suppliers investment is:

$$
\theta_{1}^{*}=\frac{\left(c+p_{C} e_{0}\right) D}{r}, \beta_{1} \in\left(\frac{5 c^{2}-p_{C}^{2} e_{0}^{2}}{8\left(c+p_{C} e_{0}\right)}, \frac{3 c-p_{C} e_{0}}{4}\right)
$$

\section{The comparison}

Results of decentralized and centralized decision making are summarized in Table 1. From Table 1 we've got a proposition2.

Table 1 comparison of decentralized and centralized decision making

\begin{tabular}{l|l|l}
\hline & decentralized & centralized \\
\hline$\pi_{S}$ & $w D+\frac{\left(c^{2}+3 p_{c}^{2} e_{0}^{2}\right) D^{2}}{8 r}$ & $w D+\frac{\left(2 \beta-c+p_{c} e_{0}\right)\left(c+p_{c} e_{0}\right) D^{2}}{2 r}$ \\
$\pi_{R}$ & $(a-w) D-b D^{2}+\frac{\left(c+p_{c} e_{0}\right)^{2} D^{2}}{4 r}$ & $(a-w) D-b D^{2}+\frac{(c-\beta)\left(c+p_{c} e_{0}\right) D^{2}}{r}$ \\
$\pi_{S+R}$ & $a D-b D^{2}+\frac{\left(3 c^{2}+4 c p_{c} e_{0}+4 p_{c}^{2} e_{0}^{2}\right) D^{2}}{8 r}$ & $a D-b D^{2}+\frac{\left(c+p_{c} e_{0}\right)^{2} D^{2}}{2 r}$ \\
$\theta^{*}$ & $\frac{\left(c+p_{c} e_{0}\right) D}{2 r}$ & $\frac{\left(c+p_{c} e_{0}\right) D}{r}$ \\
$\beta$ & $\frac{c-p_{c} e_{0}}{2}$ & $\frac{5 c^{2}-p_{c}^{2} e_{0}^{2}}{8\left(c+p_{c} e_{0}\right)}<\beta<\frac{3 c-p_{c} e_{0}}{4}$ \\
\hline
\end{tabular}

Proposition2: Emission rate in centralized decision making is twice of that in decentralized decision making under twice, and consumer appetite for low carbon increase would promote business investment efforts. Companies with higher initial carbon emissions per unit has more efforts to reduce emissions.

Proposition3: When the supplier and retailer make decisions with coordination, they can both get more profits than that in Stackelberg game if the retailer give the supplier appropriate subsidy.

\section{Conclusion}

Based on a two-stages supply chain model, consisting of one supplier and one retailer, considering carbon trade, we studied the effects of consumers' low carbon preferences and carbon emissions per unit of product to the supply chain optimal decisions under the decentralized and centralized cases.

(1) Even investing carbon emission reduction increases the cost, it enhances the income. 
(2) Company with low initial emission per unit gets more profits considering carbon trade.

(3) For the chain, it's better to encourage consumers' low carbon awareness.

(4) Company with low initial emission per unit gets more profits considering carbon trade.

(5) When the supplier and retailer make decisions with coordination, they can both get more profits than that in Stackelberg game if the retailer give the supplier appropriate subsidy.

It is to be noted that, we assumed that demand for product keeps consistent before and after carbon emission. We can explore in the case of product demand fluctuations in future research. In addition, contracts can be designed in the future research to achieve Pareto improvement.

\section{Acknowledgments}

This is where one acknowledges funding bodies etc. Note that section numbers are not required for Acknowledgments, Appendix and References.

\section{References}

[1] J. van der Geer, J.A.J. Hanraads, R.A. Lupton, The art of writing a scientific article, J. Sci. Commun. 163 (2000) 51-59.

Reference to a book:

[2] W. Strunk Jr., E.B. White, The Elements of Style, third ed., Macmillan, New York, 1979.

Reference to a chapter in an edited book:

[3] G.R. Mettam, L.B. Adams, How to prepare an electronic version of your article, in: B.S. Jones, R.Z. Smith (Eds.), Introduction to the Electronic Age, E-Publishing Inc., New York, 1999, pp. 281-304.

[4] R.J. Ong, J.T. Dawley and P.G. Clem: submitted to Journal of Materials Research (2003)

[5] P.G. Clem, M. Rodriguez, J.A. Voigt and C.S. Ashley, U.S. Patent 6,231,666. (2001)

[6] Information on http://www.weld.labs.gov.cn 